\title{
THE APPLICATION OF ENA FOR COMPARISON OF PROTECTIVE PERFORMANCE OF ZRP MODIFIED BY COMBINATION OF Zn DUST WITH ALUMINIUM OR CARBON TYPE FILLERS
}

\author{
'Boleslav EREMIÁŠ, 'Lubomír MINDOŠ, 'Libor TUREK \\ 1SVÚOM Ltd., Prague, Czech Republic, EU, eremias@svuom.cz
}

https://doi.org/10.37904/metal.2020.3543

\begin{abstract}
The possible effects on the protective performance of ZRP modified by combination of $\mathrm{Zn}$ dust with aluminium or carbon type fillers were investigated using electrochemical noise analysis (ENA). The role of different oxygen diffusion characteristics (identified on tested coating systems with ENA) on delamination tendency was tested during $168 \mathrm{hrs}$ immersion tests in $0.05 \mathrm{M} \mathrm{NaCl}$. It was shown the protective performance of tested type of coating systems can be changing with immersion time rather differently in relation to different ability of polymer matrix with the $\mathrm{Zn} / \mathrm{Al}$ or $\mathrm{Zn} / \mathrm{C}$ particles combination for oxygen transport to the coating/steel interface.
\end{abstract}

Keywords: Painting system, Zn pigment, aluminium filler, carbon filler, electrochemical noise analysis

\section{INTRODUCTION}

Most authors agree that for $\mathrm{Zn}$ pigmented epoxy coatings when speaking about the coating system the electrochemical mechanism can be considered as rather the last instance in terms of protection if $\mathrm{Zn}$ content in dry coating is lower than $80 \%$ wt. [1]. That is why very often different types of fillers are tested for partial replacement of $Z n$ in this type of coatings with the aim to improve their performance changing from sacrificial protection into dominating barrier protection. As recent findings show [2] the use of electrochemical noise analysis (ENA) has proved to be as very useful method for this purpose. By means of this method possible improvement in formulation design practices for $\mathrm{Zn}$ and Al pigmented epoxy coatings was investigated in relation to delamination tendency. It has been shown that delaminated area fraction for these steel/coating systems can probably be a measure of voids volume fraction. By this way if the ratio of pigment volume concentration (PVC) to the critical pigment volume concentration (CPVC) was sufficiently reduced (to overall pigment concentration OPVC $=$ to 45 ) high resistance to the delamination was found for tested steel/coating system. In fact as discussed earlier [3,4], locally poor dispersion can cause local volumes in a coating film to have a local PVC that exceeds the CPVC. In this case the effect of the reduced PVC - PVC/CPVC on delamination tendency should be more carefully checked for individual fillers used for partial replacement of $\mathrm{Zn}$ in $\mathrm{Zn}$ pigmented epoxy coatings even when PVC/CPVC is sufficiently reduced. To check this suggestion two different epoxy coatings were prepared with partial replacement of $\mathrm{Zn}$ by aluminium paste or carbon nanotubes suspension and decreased delamination tendency expected due to OPVC $=40$. Delamination tendency was investigated for both steel/coating systems by means of ENA during $168 \mathrm{hrs}$ immersion tests in $0.05 \mathrm{M} \mathrm{NaCl}$.

The main aim of this study was to find how much differences in local voids fraction (supposed to be identified on tested coating systems with ENA) can affect even low delamination tendency expected for this type of coating with low permeability to $\mathrm{O}_{2}$ and water. Apart from EN measurements more advanced microscopic method was used for metallographic analysis of tested coatings after immersion tests. EDX mapping and structure (SEM-SE image) of cross sections were chosen for this purpose. 


\section{EXPERIMNETAL}

\subsection{Materials}

Two types of modified Zn pigmented epoxy coatings with partial replacement of $\mathrm{Zn}$ by other type of fillers were prepared with the same value of OPVC $=40$ vol. \% but with different polymer matrix components (Table 1).

Table 1 Characteristic of ZRP modified by different types of fillers

\begin{tabular}{|c|c|c|c|c|c|}
\hline Sample & $\begin{array}{c}\text { OPVC } \\
\text { (vol\%) }\end{array}$ & Vol\% ratio Zn:filler & Filler & Binder & Hardenner \\
\hline AKAl 117 & 40 & $82: 18$ & AlumStapa 2NL & Epicote 1010 & Epicure 3115 \\
\hline NTC 77 & 40 & $93.8: 6.2$ & Epocyl NCR 128-02 & CH epoxy 222 & Telalit 160 \\
\hline
\end{tabular}

While for AKAl 117 were Al particles supplied in paste and mixed with Zn dust and epoxy resin components, for NTC 77 were carbon nanotubes supplied in special epoxy resin suspension (Nanocyl S.A., Belgium) and mixed with $\mathrm{Zn}$ dust and epoxy resin components. In order to avoid the particles settlement and for better dispersion rheological additives were used (bentonite containing the mixture of aluminosilicate was used for NTC 77 while amorphous silica was used for AKAI 117).

Both tested coating were applied by spreader bar to steel C4Q panels previously polished and degreased. The average thickness of dry film was $55 \mu \mathrm{m}$ for tested coatings.

\subsection{Method}

Immersion tests using ENA for tested coatings on steel substrate specimens were performed with use of the same experimental set-up as described earlier [5]. The potential and current noise (ENP and ENC) values (for given data set measured for given immersion time) were collected for measurement periods of $600 \mathrm{~s}$ with sampling rate of $20 \mathrm{~Hz}$ (12 000 points for period) using GAMRY ESA 410 software. Similarity of MEM Noise Impedance Spectrum characteristics with simulated electrochemical impedance spectrum for which impedance analog for coated steel is accepted [6] was used to provide information about disbonded region of the coating/steel interface in relation to double-layer capacitance $C_{d}$ values as well as delaminated corroding area $A_{d}$ values changing with immersion time t. For this purpose $A_{d}(t)$ can be estimated from $C_{d}$ values measured at given time $t(\mu \mathrm{F})$ by means of empirical equation $A_{d}=C_{d}(t) / 20$ if 20 is the typical value of the bare steel double-layer capacitance adopted to estimate the underlying metallic active surface $\left(\mu \mathrm{F} . \mathrm{cm}^{-2}\right)$ [7]. Apart from measurements in frequency domain also data treatment in time domain was performed for tested coating systems in the end of the experiments to estimate a modified noise resistance $R_{n}^{*}$ value [8]. It is believed the $R_{n}^{*}$ value will be strongly affected by the imperfections and holes in tested coatings and due to it can be able to identify differences in local voids fraction for tested coatings in the end of immersion tests.

$R_{n}^{*}$ values obtained for tested steel/coating systems in the end of the performed tests can so be compared with

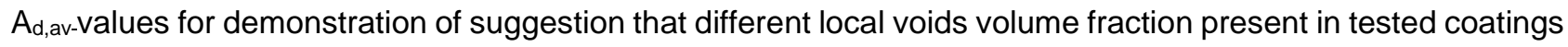
can be probably responsible for different barrier properties of film contacting the steel/coating interface during performed tests.

\section{RESULTS AND DISSCUSIONS}

Eight EN measurements were performed on type specimen AKAl 117 as well as on type specimen NTC 77 during uninterrupted immersion tests performed on steel panels coated by testing coating systems. Table 2 lists the parameters including instantaneous $C_{d}$ and $A_{d}$ values estimated for given immersion time. 
Table 2 Instantaneous $C_{d}$ and $A_{d}$ values for AKAl117 and NTC 77 after different immersion time

\begin{tabular}{|c|c|c|c|c|}
\hline \multirow{2}{*}{$\begin{array}{l}\text { Immersion time t } \\
\text { (hrs) }\end{array}$} & \multicolumn{2}{|c|}{ AKAI 117} & \multicolumn{2}{|c|}{ NTC 77} \\
\hline & $C_{d}(F)$ & $A_{d}\left(\mathrm{~cm}^{2}\right)$ & $C_{d}(F)$ & $A_{d}\left(\mathrm{~cm}^{2}\right)$ \\
\hline 29 & $6.53 \cdot 10^{-10}$ & $3.27 \cdot 10^{-5}$ & $9.76 \cdot 10^{-10}$ & $2.21 \cdot 10^{-4}$ \\
\hline 48 & $5.06 \cdot 10^{-10}$ & $2.53 \cdot 10^{-5}$ & $2.76 \cdot 10^{-9}$ & $1.38 \cdot 10^{-4}$ \\
\hline 53 & $5.23 \cdot 10^{-10}$ & $2.62 \cdot 10^{-5}$ & $3.04 \cdot 10^{-9}$ & $1.52 \cdot 10^{-4}$ \\
\hline 72 & $6.93 \cdot 10^{-10}$ & $3.63 \cdot 10^{-5}$ & $2.12 \cdot 10^{-9}$ & $1.06 \cdot 10^{-4}$ \\
\hline 77 & $1.46 \cdot 10^{-9}$ & $7.30 \cdot 10^{-5}$ & $6.29 \cdot 10^{-9}$ & $3.15 \cdot 10^{-4}$ \\
\hline 96 & $8.62 \cdot 10^{-10}$ & $4.31 \cdot 10^{-5}$ & $6.61 \cdot 10^{-9}$ & $3.31 \cdot 10^{-4}$ \\
\hline 101 & $1.03 \cdot 10^{-9}$ & $5.13 \cdot 10^{-5}$ & $4.21 \cdot 10^{-9}$ & $2.10 \cdot 10^{-4}$ \\
\hline 168 & $9.38 \cdot 10^{-10}$ & $4.70 \cdot 10^{-5}$ & $9.73 \cdot 10^{-9}$ & $2.36 \cdot 10^{-4}$ \\
\hline
\end{tabular}

Due to rather dynamic changes of cathodic nature of steel surface with the immersion time the average delaminated corroding area $\left(A_{d, a v}\right)$ time development in 168 hrs exposure of tested coatings to $0.05 \mathrm{M} \mathrm{NaCl}$ was chosen for evaluation of delamination kinetics of underlying steel. $A_{d, a v}$ development with immersion time in immersion tests using ENA and performed on tested steel/coating systems can be seen in Figure 1.

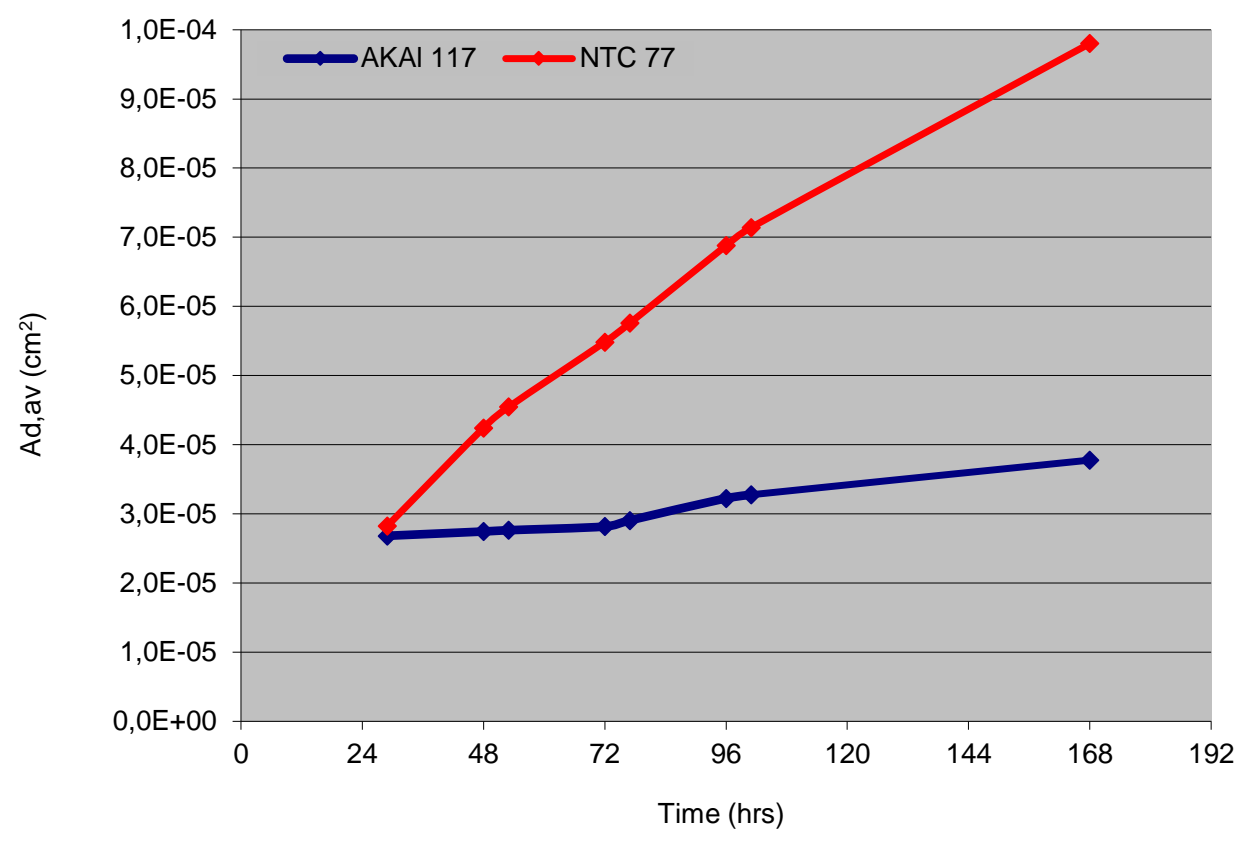

Figure 1 Time development of $A_{d, a v}$ values in $168 \mathrm{hrs}$ exposure to $0.05 \mathrm{M} \mathrm{NaCl}$

From Figure 1 can be seen significant differences in plots of the time development of $A_{d, a v}$ for AKAl 117 and NTC 77 steel/coating systems. If one wants to explain these differences it should be noticed that different microstructure of coating layers after $168 \mathrm{hrs}$ exposure in $0.05 \mathrm{M} \mathrm{NaCl}$ can be expected for NTC 77 in comparison with AKAl 117. Due to higher $R_{n}^{*}$ value (see Table 3) higher presence of more permeable areas that form a small fraction of the coating can be considered for this coating. These domains should be expected to be a more permeable than the bulk of polymer film to ionic species as $\mathrm{Na}^{+}, \mathrm{Cl}^{-}$and increase in number and permittivity as the coating absorbs water during immersion test [9]. Concerning of $\mathrm{Cl}^{-}$it should be noticed the changes in the film morphology (Figures 2 and 3) can be bigger in the longitudinal direction than in normal one. 
Table 3 Comparison of $A_{d, a v}$ values with $\mathbf{R}_{\mathbf{n}}^{*}$ values calculated from standard deviations of the potential and current noise signals $\left(\sigma_{v}\right.$ and $\left.\sigma_{I}\right)$, resp. from their means $\langle\boldsymbol{V}\rangle$ and $\langle\boldsymbol{I}\rangle$ estimated for tested steel/coating systems after 168 hrs exposure in $0.05 \mathrm{M} \mathrm{NaCl}$

\begin{tabular}{|c|c|c|c|c|r|c|}
\hline sample & $A_{d, a v}\left(\mathrm{~cm}^{2}\right)$ & $\sigma_{\mathrm{v}}(\mathrm{mV})$ & $\sigma_{\mathrm{I}}(\mathrm{nA})$ & $\langle V\rangle(\mathrm{mV})$ & $\langle I\rangle(\mathrm{nA})$ & $R_{n}^{*}(\Omega)$ \\
\hline AKAI 117 & $3.78 \cdot 10^{-5}$ & 60.739 & 0.8166 & 155.605 & 30.636 & $5.45 .10^{6}$ \\
NTC 77 & $9.80 \cdot 10^{-5}$ & 1.491 & 2.4400 & 499.553 & 5.198 & $96.10 .10^{6}$ \\
\hline
\end{tabular}

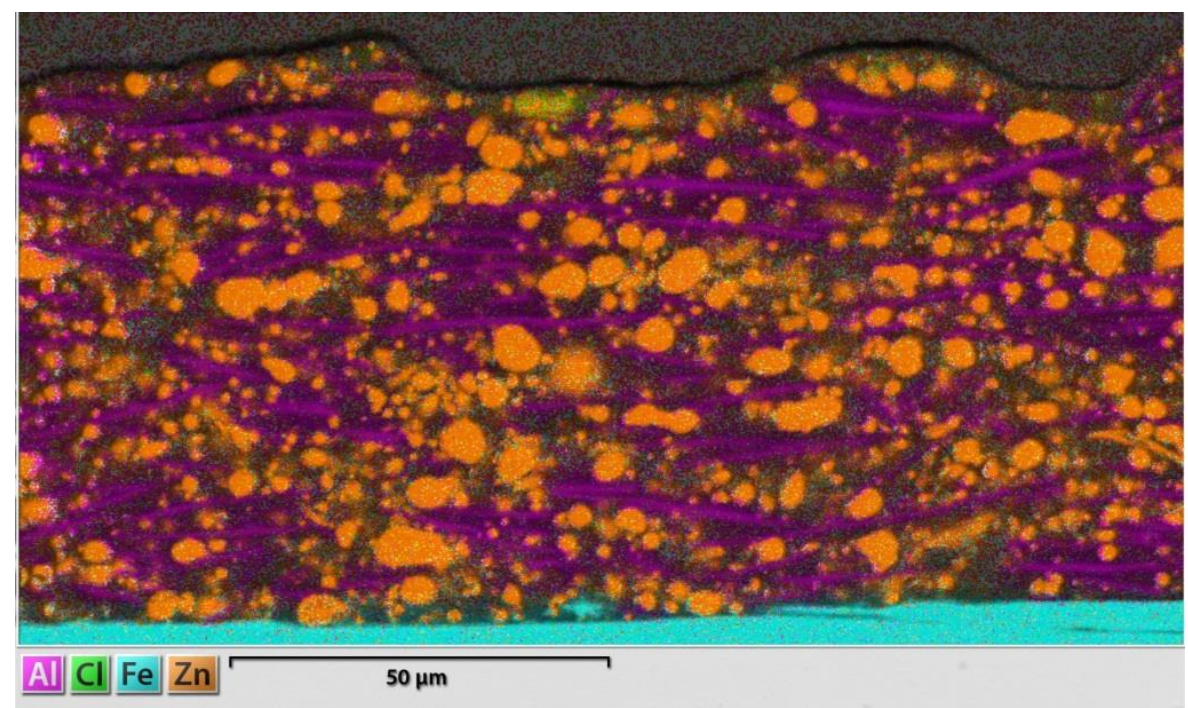

Figure 2 EDX mapping and structure (SEM-SE image) - cross sections of AKAl117 after $168 \mathrm{hrs}$ of exposure in $0,05 \mathrm{M} \mathrm{NaCl}$

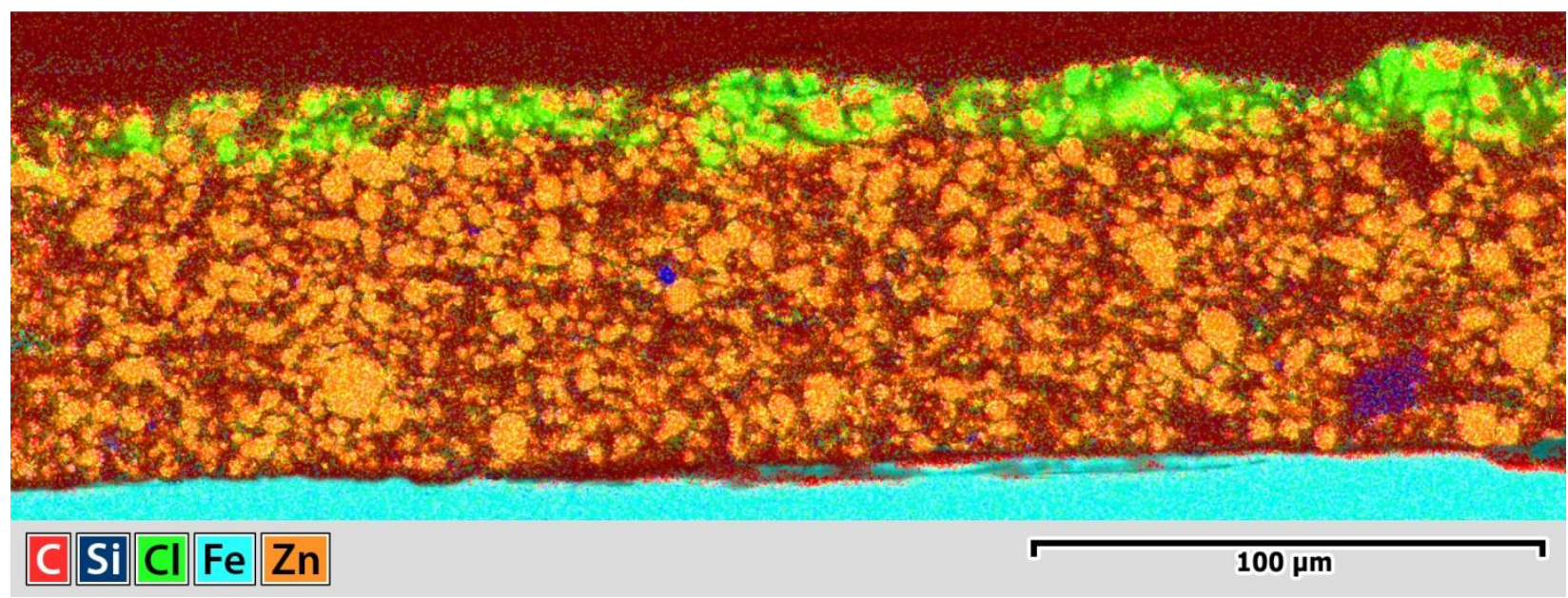

Figure 3 EDX mapping and structure (SEM-SE image) of cross sections for NTC 77 after $168 \mathrm{hrs}$ of exposure in $0.05 \mathrm{M} \mathrm{NaCl}$

It the case of NTC 77 with the small penetration of $\mathrm{Cl}^{-}$into coating along the electrolyte/coating interface it can be a result of plastizing effect triggered by the absorbed water in this coating in the end of test.

At the same time reasonable good correlation with this conclusion was found when MEM Noise Impedance Spectrum characteristics of tested coatings (MEM curves) in the end of tests were compared (Figures 4 and 5). 


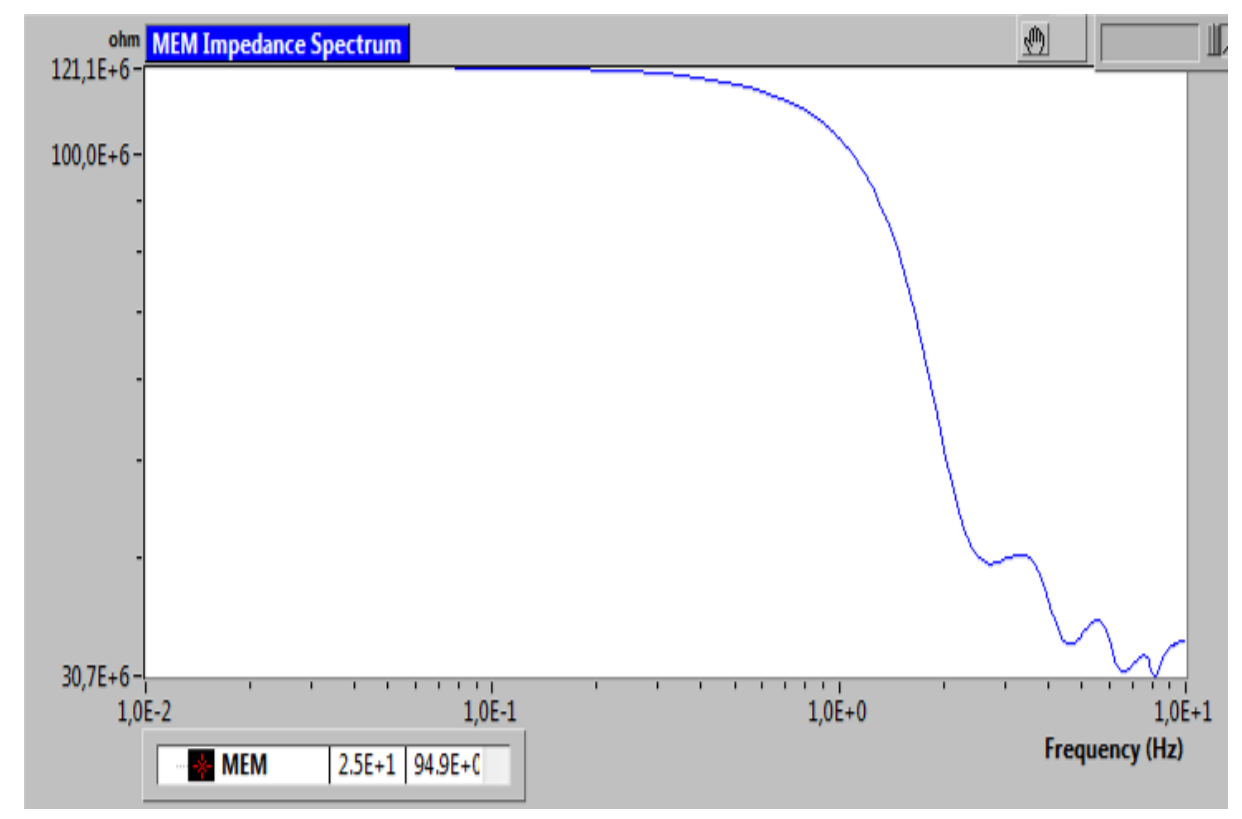

Figure 4 Noise impedance spectrum (MEM curve) for AKAl 117 after 168 hrs exposure

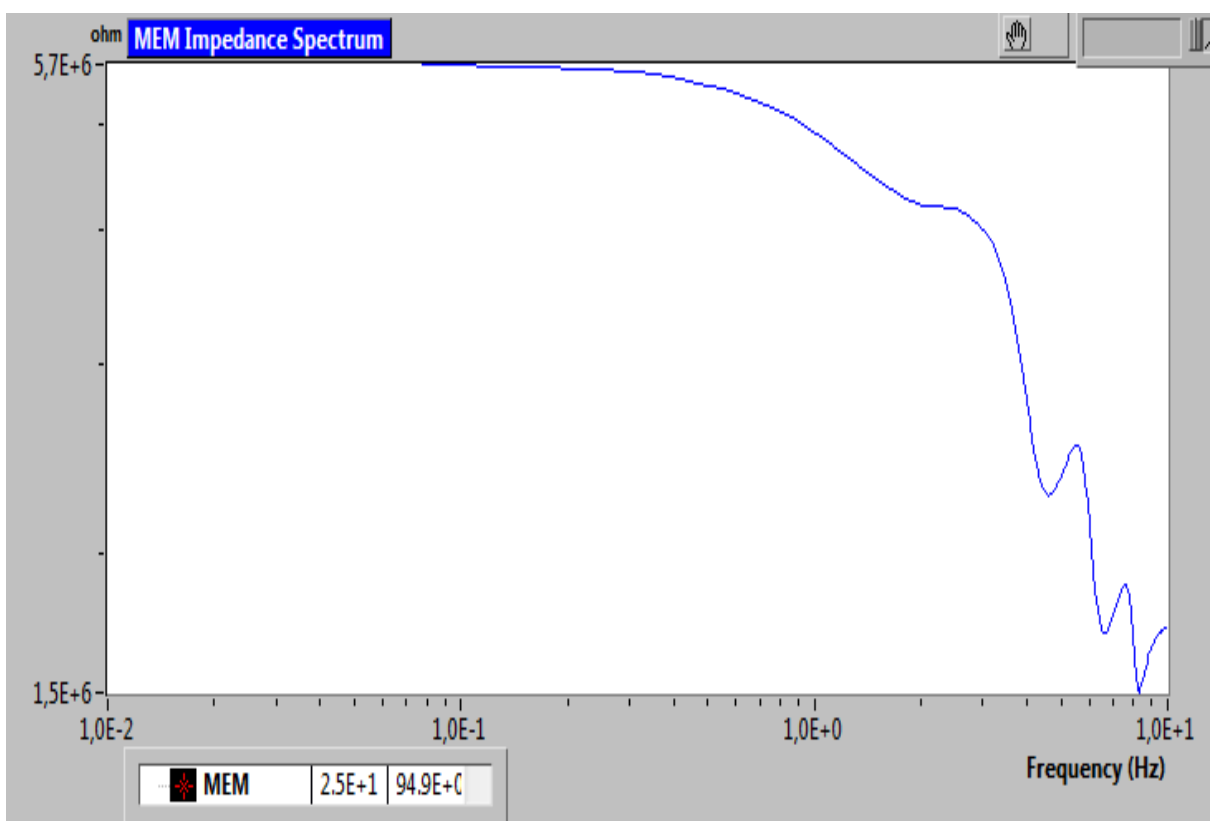

Figure 5 Noise impedance spectrum (MEM curve) for NTC 77 after 168 hrs exposure

It is obvious that for AKAl 117 with higher delamination resistance higher $\mathrm{Z}_{0.08 \mathrm{~Hz}}$ value can be attributed to some degree of competition between disbonding conditions and conditions for formation of corrosion products with passivating effect at the metallic surface beneath the coating [2].

\section{CONCLUSION}

The effect of possible differences in local voids fraction (present in epoxy coatings with partial replacement of $\mathrm{Zn}$ by other type of fillers even at OPVC $=40$ ) on differences in delamination tendency was explained using modified approach to analysis of EN data obtained during immersion tests in $0.05 \mathrm{M} \mathrm{NaCl}$. 


\section{ACKNOWLEDGEMENTS}

The study was performed and paper was written with support of project MPO - IP 8/2018.

\section{REFERENCES}

[1] ISOMINA, A.S., SAVRONOV, A.P. Effect of interphase interaction within zinc-filled composite coating on the potential of the cathodic protection of steel. Russ. J. Phys. Chem. A85, 2011.

[2] EREMIAS B., TUREK L., MINDOS L., HOCHMANNOVA L. ENA study of possible improvement in formulation design practices for optimized performance of $\mathrm{Zn}$ and Al pigmented epoxy coatings: In METAL 2019: 28th International Conference on Metallurgy and Materials. Ostrava: TANGER, 2019, pp. 1010-1015.

[3] FISHMAN, R.S., KURTZE, D.A., BIERWAGEN, G.P. The effect of density fluctuations in organic coatings. J. Appl. Phys.1992, vol. 72, no. 7, pp. 3116-3124.

[4] FISHMAN, R.S., KURTZE, D.A., BIERWAGEN, G.P. Pigment inhomogeneity and void formation in organic coatings. Progress in Organic Coating, 1993, vol. 21, no. 4, pp. 387-403.

[5] EREMIAS B., MINDOS L., TUREK L. Possibilities of ENM to evaluate anti-corrosion performance of new types of zinc rich epoxy paints in relation to ZRP formulations. In EUROCORR 2013, Frankfurt: DECHEMA, 2013, pp. 217.

[6] KENDIG M., SCULLY J. Basic Aspects of Electrochemical Impedance Application for the Life Prediction of Organic Coating on Metals. In: Corrosion. 1990, vol. 46, pp. $22-29$.

[7] ELSNER C.I., CAVALCANTI E., FERRAZ O., Di SARLI A.R. Evaluation of the Surface Treatment Effect on the Anticorrosive Performance of Paint Systems on Steel. Progress in organic coatings, 2003. vol. 48, pp. 50-62.

[8] BIERWAGEN, G.P., BALBYSHEV, V., MILLS, D., TALLMAN, D. In Proceedings of the Symposium on Advances in Corrosion Protection by Organic Coating II: Spec. Publication of the Electrochem. Society, 1995, pp. $69-81$.

[9] EREMIAS B., Unpublished results. 